\title{
Insulin-like growth factor-I has different effects on myogenin induction and cell cycle progression in human alveolar and embryonal rhabdomyosarcoma cells
}

\author{
KUNIHIKO TSUCHIYA ${ }^{1}$, HAJIME HOSOI ${ }^{1}$, AKIKO MISAWA-FURIHATA ${ }^{1}$, \\ PETER J. HOUGHTON ${ }^{2}$ and TOHRU SUGIMOTO ${ }^{1}$ \\ ${ }^{1}$ Department of Pediatrics, Graduate School of Medical Science, Kyoto Prefectural University of Medicine, \\ Kyoto, 465 Kajii-cho, Kamigyo-ku, Kyoto 602-8566, Japan; ${ }^{2}$ Department of Molecular Pharmacology, \\ St. Jude Children's Research Hospital, Memphis, TN 38105, USA
}

Received February 9, 2007; Accepted April 2, 2007

\begin{abstract}
Alveolar rhabdomyosarcoma (RMS) has a much poorer outcome than embryonal RMS. In this study, we found that IGF-I affected the induction of myogenin and cell cycle progression in alveolar RMS cells, but not in embryonal RMS cells. IGF-I enhanced the induction of myogenin protein in alveolar RMS SJ-Rh30 and KP-RMS-MS cells as it did in myoblast C2C12 cells, but not in embryonal RMS RD or KPRMS-KH cells. IGF-I induction of myogenin protein was blocked by anti-IGF-IR monoclonal antibody $\alpha$ IR-3 and the mTOR-specific inhibitor rapamycin. In Rh30mTOR-rr cells, which stably express a rapamycin-resistant mutant mTOR, rapamycin did not inhibit IGF-I induction of myogenin protein. These data suggest that IGF-I induces myogenin in alveolar RMS cells through the IGF-IR/mTOR pathway. In C2C12 cells, IGF-I induces myogenin protein followed by cell cycle arrest leading to myogenic differentiation. IGF-I promoted G1-S cell cycle progression without any signs of terminal differentiation in alveolar RMS cells. On the other hand, IGF-I promoted neither cell cycle arrest nor G1-S cell cycle progression in embryonal RMS cells. In alveolar RMS SJ-Rh30 cells, 4E-BP1, one of two effectors downstream of mTOR, was continuously hyperphosphorylated by IGF-I, whereas in embryonal RMS RD cells, 4E-BP1 was only transiently hyperphosphorylated. These findings suggest that the different effects
\end{abstract}

Correspondence to: Dr Hajime Hosoi, Department of Pediatrics, Kyoto Prefectural University of Medicine, 465 Kajii-cho, Kamigyoku, Kyoto 602-8566, Japan

E-mail: hhosoi@koto.kpu-m.ac.jp

Abbreviations: IGF, insulin-like growth factor; IGF-IR, IGF-I receptor; mTOR, mammalian target of rapamycin; PI3K, phosphoinositide 3-kinase; p38MAPK, mitogen-activated protein kinase; RMS, rhabdomyosarcoma

Key words: rhabdomyosarcoma, IGF-I, 4E-BP1, myogenin, cell cycle progression of IGF-I on myogenin induction and cell cycle progression in alveolar and embryonal RMS cells are due to a difference of phosphorylation status of 4E-BP1. These different responses to IGF-I help to explain immunohistochemical and clinical behavioral differences between alveolar and embryonal RMS.

\section{Introduction}

Rhabdomyosarcoma (RMS) is the most common soft tissue tumor of childhood and adolescents (1). Although the survival rate has significantly improved as a result of the use of intensive therapy combined with surgery, radiation and chemotherapy, alveolar RMS, one of the two major subtypes of RMS, still has a poor prognosis compared with the other subtype, embryonal RMS (2). Approximately $60 \%$ of alveolar RMS cases are characterized by the recurrent translocation $\mathrm{t}(2 ; 13)(\mathrm{q} 35 ; \mathrm{q} 14)$, which juxtaposes the 5'DNA binding domain-encoding sequence of the $P A X 3$ gene with the $3^{\prime}$ sequence of the $F K H R$ gene, to generate the chimeric gene $P A X 3-F K H R(3,4)$. Several studies have reported that the presence of $P A X 3-F K H R$ was an adverse prognostic factor in alveolar RMS $(5,6)$. cDNA microarrays have revealed that PAX3-FKHR-overexpressing NIH3T3 cells overexpress myogenin and igf 2 , suggesting that myogenin and igf2 are activated downstream of PAX3-FKHR (7).

Myogenin belongs to a group of myogenic regulatory proteins, the MyoD family (MyoD, myogenin, myf-5, and MRF-4) (8-12) and acts as a transcriptional activator of genes that encode skeletal muscle-specific proteins containing the myosin heavy chain (11). Myogenin knockout mice have been shown to have severe muscle deformity at birth $(13,14)$. In cultured mouse myoblast $\mathrm{C} 2 \mathrm{C} 12$ cells, myogenin protein and myogenic differentiation are induced by serum withdrawal (15-17). Insulin-like growth factors (IGFs) I and II appear to stimulate myogenesis in cultured myogenic cells, suggesting that they are required for normal skeletal muscle development during embryogenesis (15). IGFs appear to stimulate myogenesis by regulating myogenin protein induction (15-17). Almost all RMS samples show some degree of immunostaining with myogenin antibodies while non-RMS pediatric tumors are consistently negative (18-21). In addition, almost all alveolar 
RMS samples show strong positive staining for myogenin, whereas embryonal RMS samples show weak and patchy staining for myogenin, and a large proportion of tumor cells are negative for myogenin (18-21).

On the other hand, in numerous carcinomas as well as malignant sarcomas including RMS, IGFs also act as growth/ survival factors (22). RMS cells produce IGF-II and express IGF-I receptor (IGF-IR), suggesting that an autocrine pathway plays a role in regulating the growth of these cells $(23,24)$. Furthermore, down-regulation of the IGF/IGF-IR pathway, through blocking ligand binding to the IGF-IR, was found to suppress the proliferation of RMS cells both in vitro and in vivo (25). Suppression of the IGF signaling pathway by IGF-IR antisense mRNA also resulted in the inhibition of RMS cell growth (26). We previously reported that mTOR, one of the molecular targets downstream of IGF-IR, plays a major role in the proliferation and survival of RMS cells and that an mTOR-specific inhibitor, rapamycin, blocks the proliferation and induces apoptosis of tumor cells $(27,28)$. It remains unclear why alveolar RMS cells aggressively proliferate and easily invade surrounding tissue and why distant metastasis occurs without terminal differentiation in spite of its overexpression of IGF-IR, IGF-II and myogenin.

In this study, we investigated the responses of alveolar RMS cells and embryonal RMS cells to serum-starvation and IGF-I stimulation and which signaling pathways downstream of IGF-IR are responsible for the responses.

\section{Materials and methods}

Cell culture and reagents. Six cell lines were used in this study: mouse myoblast C2C12 cells (American Type Culture Collection, Manassas, VA), human alveolar RMS cell lines SJ-Rh30 (Rh30) and KP-RMS-MS (MS), both of which express the $P A X 3-F K H R$ chimeric gene, human embryonal RMS cell lines RD and KP-RMS-KH(KH), neither of which express the PAX3-FKHR chimeric gene, and Rh30mTOR-rr cells, which stably express a rapamycin-resistant mutant mTOR gene as well as the $P A X 3-F K H R$ gene (28). The cells were maintained in DMEM containing $10 \%$ fetal bovine serum (FBS) at $37^{\circ} \mathrm{C}$ in a $5 \% \mathrm{CO}_{2}$ incubator. The mouse monoclonal antibody to myogenin was purchased from IMGENEX (San Diego, CA). The rabbit polyclonal antibodies to Ser 473 phospho-specific Akt, total Akt, and 4EB-P1 were purchased from Cell Signaling Technology (Beverly, MA). The rabbit polyclonal antibody to $\mathrm{p} 70 \mathrm{~s} 6 \mathrm{k}$ was purchased from Santa Cruz Biotechnology (Santa Cruz, CA). The mouse monoclonal antibody to $B$-actin, IGF-I, and rapamycin were obtained from Sigma Chemical Co. (St. Louis, MO). IGF-IR blocking antibody ( $\alpha$ IR3) was purchased from Oncogene Science (Cambridge, MA). Horseradish peroxidase-conjugated antimouse IgG and antirabbit IgG were obtained from Amersham (Arlington, IL). Rapamycin was added $15 \mathrm{~min}$ prior to stimulation with IGF-I and $\alpha$ IR3, and SB203580 (Calbiochem) was added $1 \mathrm{~h}$ prior to stimulation.

Western blot analysis. Cells were plated into $2 \mathrm{ml}$ of medium at a density of $5 \times 10^{5}$ cells $/ 35-\mathrm{mm}$ well in six-well plates, incubated overnight at $37^{\circ} \mathrm{C}$ and $5 \% \mathrm{CO}_{2}$, serum-starved, incubated with IGF-I $(50 \mathrm{ng} / \mathrm{ml})$ in the absence or presence
A
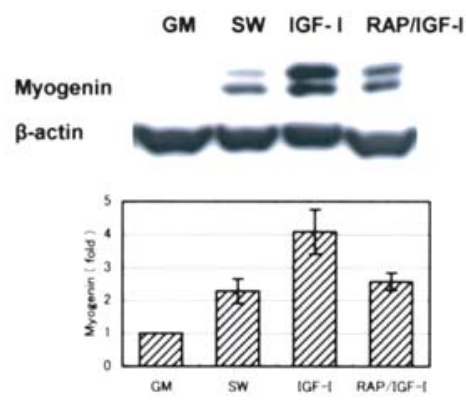

B

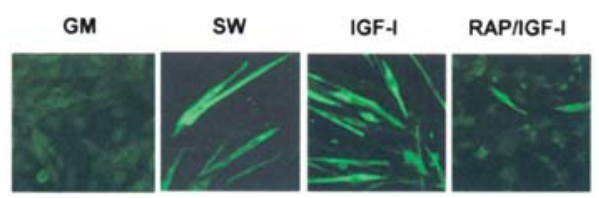

Figure 1. mTOR mediates both myogenin expression and myogenic differentiation induced by serum withdrawal and IGF-I in C2C12 murine myoblast cells. $\mathrm{C} 2 \mathrm{C} 12$ cells were serum-fasted and then stimulated with IGF-I $(50 \mathrm{ng} / \mathrm{ml})$ in the absence or presence of rapamycin $(100 \mathrm{ng} / \mathrm{ml})$. (A) After $48 \mathrm{~h}$, whole lysates were subjected to Western blot analysis to determine myogenin expression. The levels of myogenin protein were normalized against $\beta$-actin (mean $\pm \mathrm{SE}, \mathrm{n}=3$ ). (B) After $72 \mathrm{~h}$, the cells on cover slips were fixed and stained with anti-myosin heavy chain. GM, growth medium (10\% FBS medium); SW, serum withdrawal; IGF-I, cells were stimulated with IGF-I; RAP/IGF-I, cells were stimulated with IGF-I in the presence of rapamycin.

of either rapamycin $(100 \mathrm{mg} / \mathrm{ml})$ or $\alpha \mathrm{IR} 3(0.5 \mu \mathrm{g} / \mathrm{ml})$ and lysed as described previously (29). Whole cell lysates were separated by SDS-polyacrylamide gel electrophoresis and transferred to an Immobilon-P membrane (Millipore Corp., Bedford, MA). The membrane was blocked for $1 \mathrm{~h}$ in phosphate-buffered saline-Tween 20 (PBS-T) with 5\% nonfat dry milk, incubated with the primary antibodies, washed in PBS-T, and incubated with the appropriate secondary antibodies. Antibody binding was detected by using the enhanced ECL detection system (Amersham).

The levels of myogenin protein were quantified by $\mathrm{NIH}$ Image Software 1.55 (NIH, Bethesda, MD) and were normalized against the levels of $\beta$-actin protein. Values are the mean $\pm \mathrm{SE}$ of results from three separate experiments.

Cell cycle analysis. Cells $\left(3 \times 10^{6}\right)$ were seeded in $100-\mathrm{mm}$ dishes, incubated overnight, serum-fasted for $24 \mathrm{~h}$, incubated with IGF-I $(50 \mathrm{ng} / \mathrm{ml})$ for $48 \mathrm{~h}$, harvested by trypsinization, washed once in PBS, resuspended in $50 \mathrm{mg} / \mathrm{ml}$ propidium iodide solution containing $200 \mu \mathrm{g} / \mathrm{ml}$ boiled Rnase, incubated at room temperature for $30 \mathrm{~min}$ in the dark, and analysed by flow cytometry using a Becton Dickinson FACScan. Cell cycle distribution was determined with the ModiFit software (Verity Software House Inc., Topshame, ME).

Detection of myosin heavy chain by immunofluorescence. Cells on cover slips were fixed with absolute methanol, washed and incubated with the mouse monoclonal anti-myosin heavy chain antibody (15 $\mu \mathrm{g} / \mathrm{ml}$; Sigma) for $1 \mathrm{~h}$, rinsed with PBS, incubated with fluorescein isothiocyanate-conjugated antimouse IgG (1:80; Santa Cruz) for $1 \mathrm{~h}$, and examined under an inverted fluorescence microscope. 
A

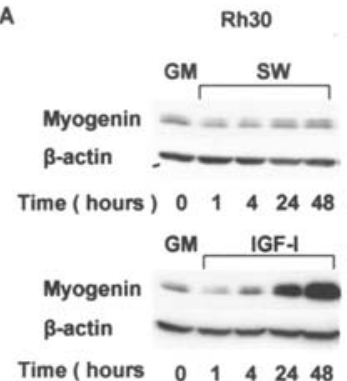

B

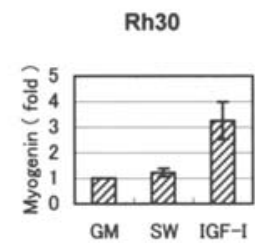

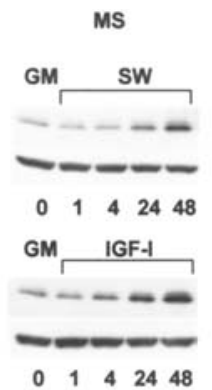

MS

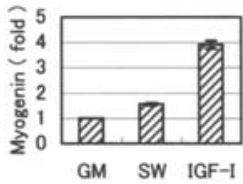

Figure 2. IGF-I, but not serum withdrawal induces myogenin in human alveolar rhabdomyosarcoma, Rh30 and KP-RMS-MS cells. (A) Time-course of myogenin expression with either serum withdrawal or IGF-I stimulation in Rh30 and KP-RMS-MS. Cells were serum-fasted and then stimulated with IGF-I $(50 \mathrm{ng} / \mathrm{ml})$ for the times indicated. (B) The levels of myogenin protein were normalized against $\beta$-actin (mean $\pm \mathrm{SE}, \mathrm{n}=3$ ). GM, growth medium (10\% FBS medium); SW, serum withdrawal; IGF-I, cells were stimulated with IGF-I.

\section{Results}

IGF-I enhances both myogenin expression and myogenic differentiation induced by serum withdrawal through the mTOR pathway in C2C12 cells. In mouse $\mathrm{C} 2 \mathrm{C} 12$ myoblasts after $48 \mathrm{~h}$ of serum withdrawal, the level of myogenin (Fig. 1A, upper panel, SW) was $2.28( \pm 0.37)$-fold greater than the level produced in the presence of 10\% FBS (GM). The level of myogenin after $48 \mathrm{~h}$ of serum withdrawal in the presence of IGF-I (Fig. 1A, upper panel, IGF-I) was $4.08( \pm 0.67)$-fold greater than the levels produced in the presence of $10 \%$ FBS (GM). In other words, after $48 \mathrm{~h}$ of incubation in the presence of IGF-I $(50 \mathrm{ng} / \mathrm{ml})$, the level of myogenin protein was 1.79 $( \pm 0.67)$-fold higher than the level induced by serum withdrawal. Similar results were reported previously (15-17). IGF-I induction of myogenin protein was decreased by rapamycin (100 ng/ml) to the level induced by serum withdrawal (Fig. 1A, upper panel, RAP/IGF-I).

In $\mathrm{C} 2 \mathrm{C} 12$ cells, a serum-free condition for $72 \mathrm{~h}$ induced morphological differentiation and myosin heavy chain expression. IGF-I $(50 \mathrm{ng} / \mathrm{ml})$ enhanced both morphological differentiation and myosin heavy chain expression. Rapamycin $(100 \mathrm{ng} / \mathrm{ml})$ inhibited myogenic differentiation both by serum withdrawal and IGF-I (Fig. 1B).

IGF-I induces myogenin protein in human alveolar RMS SJRh30 and KP-RMS-MS cells. In the human alveolar RMS cell lines SJ-Rh30 (Rh30) and KP-RMS-MS (MS), both of which have the chimeric gene $P A X 3-F K H R$, serum withdrawal for $48 \mathrm{~h}$ had a little effect on myogenin induction: the levels of myogenin after $48 \mathrm{~h}$ of serum withdrawal (Fig. 2A, upper panels, right lanes, SW) were $1.22( \pm 0.16)$-fold and 1.56 $( \pm 0.05)$-fold, respectively, greater than the level produced in the presence of $10 \%$ FBS (Fig. 2A, upper panels, left lanes, GM).
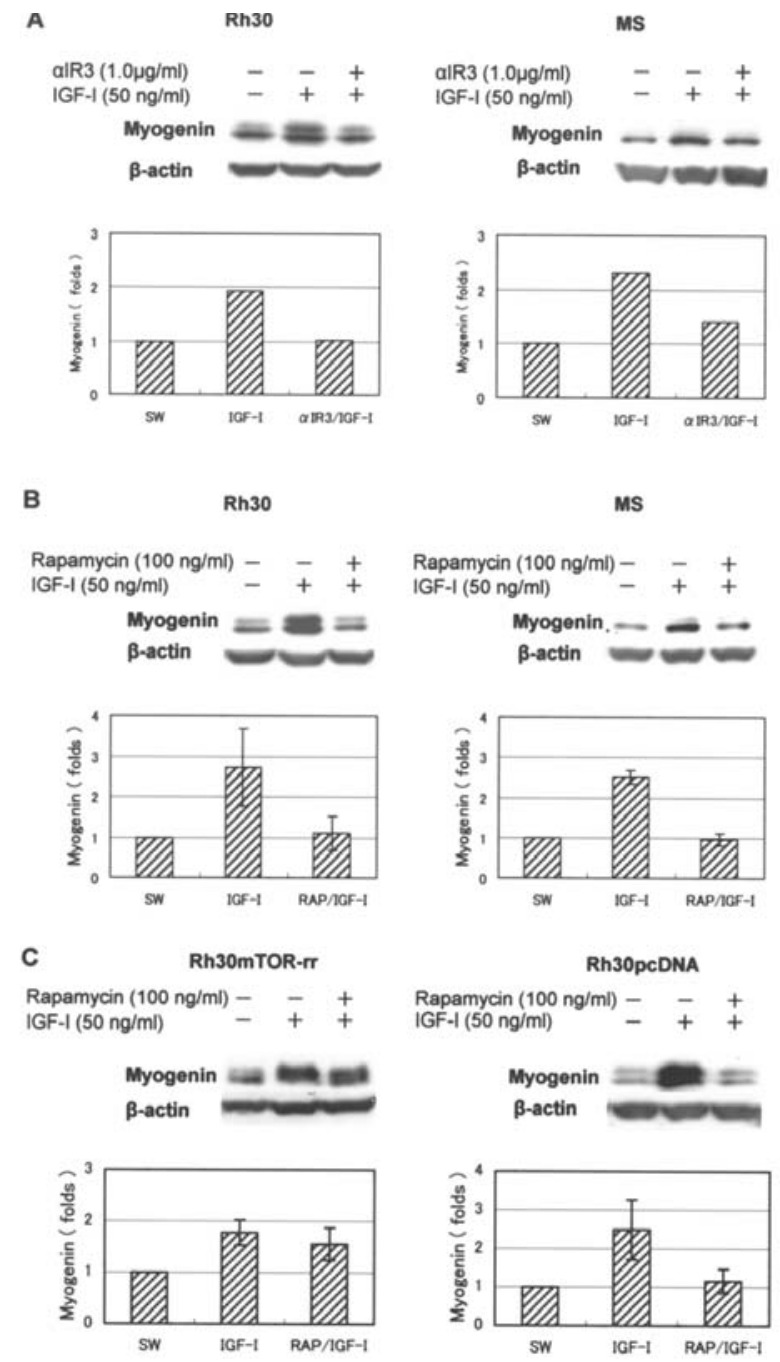

Figure 3. IGF-I induction of myogenin in alveolar RMS Rh30 and KPRMS-MS cells is mediated mainly through the IGF-IR/mTOR pathway. Serum-fasted Rh30 and KP-RMS-MS (MS) cells were preincubated with $\alpha$-IR3 $(0.5 \mu \mathrm{g} / \mathrm{ml})(\mathrm{A})$ or rapamycin $(100 \mathrm{ng} / \mathrm{ml})(\mathrm{B})$. Cells were then incubated with IGF-I $(50 \mathrm{ng} / \mathrm{ml})$ for $48 \mathrm{~h}$. Whole lysates were subjected to Western blot analysis to determine myogenin expression. B-actin was used as an internal control. (C) Serum-fasted Rh30mTOR-rr and Rh30pcDNA cells were preincubated with rapamycin $(100 \mathrm{ng} / \mathrm{ml})$. Cells were then incubated with IGF-I $(50 \mathrm{ng} / \mathrm{ml})$ for $24 \mathrm{~h}$. Whole lysates were subjected to Western blot analysis to determine myogenin expression. ß-actin was used as an internal control.

On the other hand, IGF-I $(50 \mathrm{ng} / \mathrm{ml})$ induced a remarkable increase of myogenin protein; the levels of myogenin in Rh30 cells and MS cells after $48 \mathrm{~h}$ of serum withdrawal in the presence of IGF-I (Fig. 2A, lower panels, right lanes, IGF-I) were $3.25( \pm 0.72)$ and $3.91( \pm 0.16)$-fold, respectively, greater than the levels produced in the presence of $10 \%$ FBS (Fig. 2A, lower panels, left lanes, GM).

aIR-3 inhibits IGF-I-induced myogenin protein expression. $\alpha$ IR-3 $(1.0 \mu \mathrm{g} / \mathrm{ml})$ inhibited myogenin protein expression in alveolar RMS Rh30 and MS cells induced by IGF-I (50 ng/ml) to the level of the expression obtained in serum-starved condition (Fig. 3A, upper panels, middle lanes and lower panels, $\alpha$ IR3/IGF-I), confirming that IGF-IR is involved in myogenin protein induction by IGF-I in these cells. 


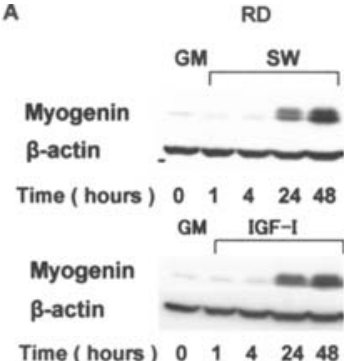

B

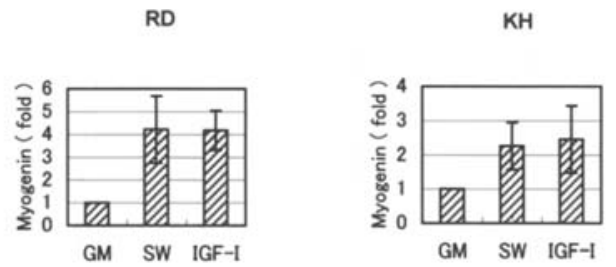

C
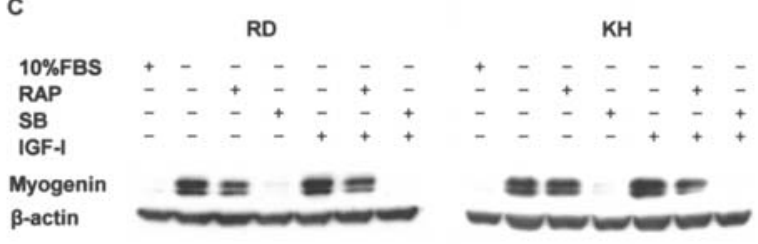

D

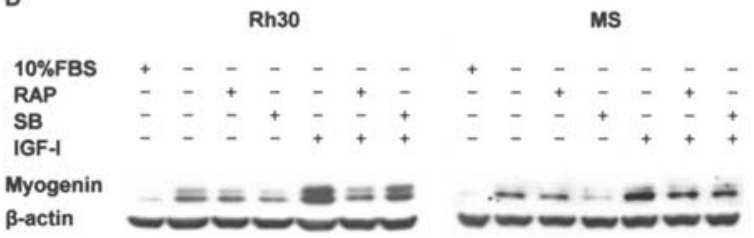

Figure 4. Serum withdrawal, but not IGF-I induces myogenin in embryonal RMS, RD and KP-RMS-KH cells. Serum withdrawal induces myogenin protein mainly through the p38MAPK pathway in embryonal RMS cells, but not in alveolar RMS cells. (A) Time-course of myogenin expression with either serum withdrawal or IGF-I stimulation in RD and KP-RMS-KH (KH). Cells were serum-fasted and then stimulated with IGF-I $(50 \mathrm{ng} / \mathrm{ml})$ for the times indicated. (B) The levels of myogenin protein were normalized against $B$-actin (mean $\pm \mathrm{SE}, \mathrm{n}=3$ ). GM, growth medium (10\% FBS medium); SW serum withdrawal; IGF-I, cells were stimulated with IGF-I. Serum-fasted $\mathrm{RD}$ and KP-RMS-KH (KH) cells (C) and Rh30 and KP-RMS-MS (MS) (d) were preincubated with rapamycin $(100 \mathrm{ng} / \mathrm{ml})$ or SB203580 $(10 \mu \mathrm{M})$. Cells were then incubated with IGF-I $(50 \mathrm{ng} / \mathrm{ml})$ for $48 \mathrm{~h}$. Whole lysates were subjected to Western blot analysis to determine myogenin expression. B-actin was used as an internal control.

Rapamycin inhibits IGF-I-induced myogenin protein expression in alveolar RMS Rh30 and MS cells. In Rh30 and MS cells, IGF-I (50 ng/ml) induced a remarkable increase of myogenin protein up to $48 \mathrm{~h}$ (Fig. 2B, upper panels, middle lines) and demonstrated a maximum increase of $2.72( \pm 0.95)$ and 2.51 $( \pm 0.18)$-fold at $48 \mathrm{~h}$, respectively, compared with the values of myogenin protein induced by serum withdrawal (Fig. 3B, lower panels, IGF-I).

After $48 \mathrm{~h}$ in the presence of $100 \mathrm{ng} / \mathrm{ml}$ rapamycin, induction of myogenin protein in Rh30 and MS cells by IGF-I decreased to the levels induced by serum withdrawal (Fig. 3B).

Rapamycin does not inhibit IGF-I-induced myogenin protein expression in Rh30mTOR-rr cells resistant to rapamycin. To confirm that mTOR affects IGF-I induction of myogenin

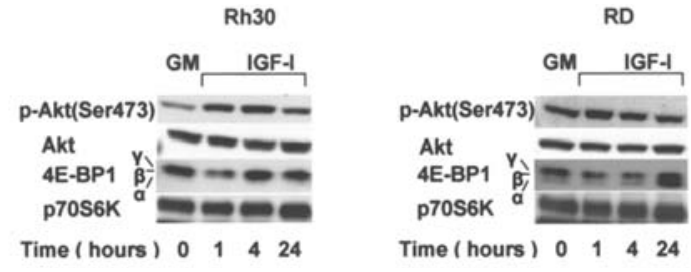

Figure 5. IGF-I phosphorylates Akt, 4E-BP1 and p70s6k in alveolar RMS Rh30 cells and embryonal RMS RD cells. Serum-starved cells were stimulated with IGF-I $(50 \mathrm{ng} / \mathrm{ml})$ for the times indicated. Phosphorylated Akt was detected with a phospho-specific Akt antibody. Blots were stripped and reprobed with antibody that recognizes Akt regardless of its phosphorylation state. Phosphorylation of p70s6k and 4E-BP1 was evaluated with a gel mobility shift. Three 4E-BP1 bands represent various isoforms with $\alpha$ being basally phosphorylated and $\gamma$ being hyperphosphorylated.

protein, we used Rh30mTOR-rr cells that were stably expressing a rapamycin-resistant mutant mTOR. IGF-I (50 ng/ml) induced a remarkable increase of myogenin protein in Rh30mTOR-rr cells as it did in parent Rh30 cells, and rapamycin $(100 \mathrm{ng} / \mathrm{ml})$ did not decrease the induction; the levels of myogenin protein induced by IGF-I in the absence and presence of rapamycin were $1.48( \pm 0.05)$ and $1.20( \pm 0.12)$-fold greater, respectively, than the values of myogenin protein induced by serum withdrawal (Fig. 3C, left panels). On the other hand, IGF-I induction of myogenin protein in Rh30pcDNA cells that were transfected with an empty vector alone was decreased by rapamycin to the level induced by serum withdrawal (Fig. 3C, right panels).

Serum withdrawal induces myogenin protein, whereas IGF-I does not enhance the induction in embryonal RMS RD and $K P-R M S-K H$ cells. On the other hand, in embryonal RMS RD and KP-RMS-KH $(\mathrm{KH})$ cells, which do not have the chimeric gene $P A X 3-F K H R$, serum withdrawal induced myogenin protein. After $48 \mathrm{~h}$ in a serum-free condition, myogenin protein levels in embryonal RMS RD and KH cells were $4.22( \pm 1.47)$ and $2.26( \pm 0.69)$-fold greater, respectively, than the levels produced in the presence of 10\% FBS (GM) [Fig. 4A (upper panels) and B (SW and GM)]. However, IGF-I (50 ng/ml) did not cause an additional induction of myogenin protein [Fig. 4A (lower panels) and B (IGF-I)].

In embryonal RMS RD and KH cells, SB203580 inhibits serum withdrawal-induced and IGF-I-induced myogenin protein. The p38MAPK pathway was previously shown to play a role in myogenesis in non-tumor mouse myoblast cells (30-33). To examine whether this pathway was involved in IGF-I induction of myogenin protein, we used a p38MAPK inhibitor, SB203580. SB203580 $(10 \mu \mathrm{M})$ completely inhibited myogenin protein induction by both serum withdrawal and IGF-I $(50 \mathrm{ng} / \mathrm{ml})$ in embryonal RMS RD and KH cells (Fig. 4C). On the other hand, SB203580 (10 $\mu \mathrm{M})$ did not appear to inhibit induction of myogenin protein by IGF-I in human alveolar RMS Rh30 and MS cells (Fig. 4D).

IGF-I phosphorylates 4E-BPI continuously in alveolar RMS Rh30 cells, but transiently in embryonal RMS RD cells. Akt, 4E-BP1 and p70s6k have been identified as effectors on the IGF-IR/PI3K/mTOR signaling pathway (34-37). In both 

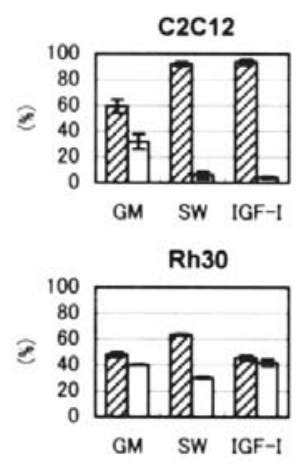

RD

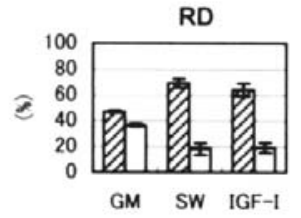

$\mathrm{GO} /$

S

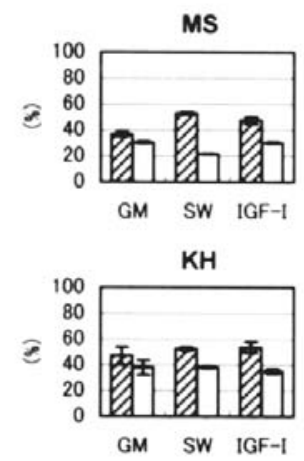

B

\begin{tabular}{|l|c|c|c|c|c|c|}
\hline \multirow{2}{*}{ Cell Line } & \multicolumn{3}{|c|}{ G0/1 (\%) } & \multicolumn{3}{c|}{ S $\%)$} \\
\cline { 2 - 7 } & GM & SW & IGF-I & GM & SW & IGF-I \\
\hline $\mathrm{C} 2 \mathrm{C} 12$ & $59.2 \pm 5.0$ & $92.0 \pm 1.6$ & $93.6 \pm 2.0$ & $31.8 \pm 5.7$ & $6.11 \pm 3.0$ & $4.3 \pm 0.9$ \\
\hline Rh30 & $48.1 \pm 2.0$ & $63.3 \pm 0.9$ & $45.6 \pm 1.7$ & $40.1 \pm 0.5$ & $30.3 \pm 0.7$ & $42.1 \pm 2.7$ \\
\hline MS & $36.4 \pm 1.6$ & $53.0 \pm 0.9$ & $47.5 \pm 2.7$ & $30.6 \pm 1.0$ & $21.4 \pm 0.3$ & $30.3 \pm 0.8$ \\
\hline RD & $46.8 \pm 1.3$ & $69.2 \pm 3.5$ & $63.9 \pm 5.1$ & $36.4 \pm 1.0$ & $18.2 \pm 4.5$ & $19.1 \pm 3.7$ \\
\hline KH & $47.0 \pm 7.0$ & $52.5 \pm 1.3$ & $53.5 \pm 4.1$ & $38.0 \pm 5.6$ & $37.9 \pm 0.8$ & $35.1 \pm 1.9$ \\
\hline
\end{tabular}

C

GM

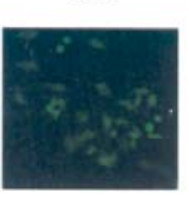

RD
SW
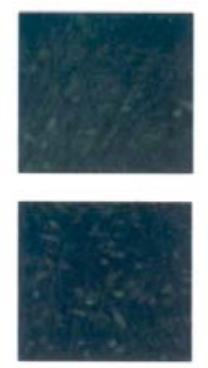

IGF-I
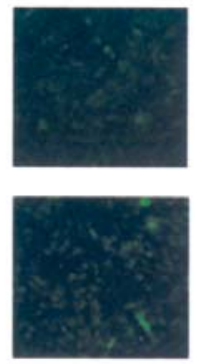

Figure 6. Myogenin induction does not induce myogenic differentiation in either alveolar or embryonal RMS cells. (A) Serum-starved C2C12, Rh30, KP-RMS-MS (MS), RD and KP-RMS-KH (KH) cells were incubated with or without IGF-I $(50 \mathrm{ng} / \mathrm{ml})$. After propidium iodide staining, the cell cycle distributions were determined (mean \pm SE, $n=3$ ). (B) Effects of FBS and IGF-I on percent of cells of various cell types in different phases of the cell cycle. (C) Rh30 and RD cells were serum-fasted and then stimulated with IGI-I $(50 \mathrm{ng} / \mathrm{ml})$ in the absence or presence of rapamycin $(100 \mathrm{ng} / \mathrm{ml})$. After $72 \mathrm{~h}$, the cells on cover slips were fixed and stained with anti-myosin heavy chain. GM, growth medium (10\%FBS medium); SW, serum withdrawal; IGF-I, cells were stimulated with IGF-I; RAP/IGF-I, cells were stimulated with IGF-I in presence of rapamycin.

alveolar RMS Rh30 cells and embryonal RMS RD cells, Akt and p70s6k were phosphorylated continuously at least for $24 \mathrm{~h}$ after stimulation with $50 \mathrm{ng} / \mathrm{ml}$ of IGF-I (Fig. 5, left panel, Akt and p70s6k), although the phosphorylation of Akt and p70s6k peaked at 1-4 h after the stimulation (Fig. 5, right panel, Akt and p70s6k). However, 4E-BP1, the other effector downstream of mTOR was continuously phosphorylated up to $24 \mathrm{~h}$ by IGF-I in Rh30 cells, whereas in RD cells the phosphorylation by IGF-I stimulation was only transient showing the dephosphorylation at $24 \mathrm{~h}$ (Fig. 5, 4E-BP1). IGF-I maintained 4E-BP1 hyperphosphorylation as shown by the

signal of the hyperphosphorylated form $(\gamma)$ without any increase of the less-phosphorylaed form $(\beta, \alpha)$ at least for $24 \mathrm{~h}$ after IGF-I stimulation in Rh30 cells (Fig. 5, left panel, 4E-BP1), whereas $\beta-4 \mathrm{E}-\mathrm{BP} 1$ and $\alpha-4 \mathrm{E}-\mathrm{BP} 1$ began to increase at $4 \mathrm{~h}$ after IGF-I stimulation in RD cells (Fig. 5, right panel, 4E-BP1).

IGF-I induces cell cycle arrest in C2C12 cells, but not in alveolar or embryonal RMS cells. Serum withdrawal as well as IGF-I induced cell cycle arrest and myogenic differentiation in $\mathrm{C} 2 \mathrm{C} 12$ cells (Fig. 6A). FACS analysis demonstrated that the percent of $\mathrm{C} 2 \mathrm{C} 12$ cells that were in the $\mathrm{G} 0 / \mathrm{G} 1$ phase was $59.2 \%$ in $10 \%$ FBS medium, $92.0 \% 24 \mathrm{~h}$ after serum withdrawal, and 93.6\% $24 \mathrm{~h}$ after IGF-I stimulation (Fig. 6B). On the other hand, serum withdrawal increased the G0/G1 population only modestly in alveolar RMS Rh30 and MS cells and in embryonal RMS RD and KH cells (Fig. 6A and B). Further, IGF-I did not induce G0/G1 cell cycle arrest in either alveolar or embryonal RMS cells, but it did induce G1-S cell cycle progression in alveolar RMS cells (Fig. 6A and B).

Neither Rh30 cells nor RD cells show myogenic terminal differentiation. In mouse myoblast $\mathrm{C} 2 \mathrm{C} 12$ cells, myosin heavy chain expression was observed after $72 \mathrm{~h}$ of serum withdrawal condition and was enhanced by IGF-I $(50 \mathrm{ng} / \mathrm{ml})$. However, neither Rh30 cells nor RD cells expressed myosin heavy chain during either serum withdrawal or IGF-I $(50 \mathrm{ng} / \mathrm{ml})$ treatment up to 72 h (Fig. 6C).

\section{Discussion}

Because alveolar RMS has an extremely poor outcome, even with the newest multimodal therapy, it is necessary to find a biological characteristic that is specific to alveolar RMS in order to develop a new treatment. In alveolar RMS, the chimeric gene $P A X 3-F K H R$ has been widely accepted as an indicator of poor prognosis. Myogenin has been reported to be expressed in alveolar RMS at a much higher rate than in embryonal RMS in paraffin-embedded tissues (18-21). Myogenin is a member of the MyoD family, whose members regulate the myogenic differentiation program (8-12) IGFs are reported to stimulate myogenesis by inducing the expression of myogenin as one of the molecular mechanisms of skeletal muscle differentiation (15-17). IGFs (IGF-I and -II) strongly stimulate myogenesis in cultured myogenic cells and are required for normal skeletal muscle development during embryogenesis (15-17). IGFs regulate myogenic differentiation mainly at the level of myogenin gene transcription via phosphoinositide 3-kinase (PI3K) and mTOR (15). Although embryonal RMS RD cells have some defects in the IGF-IR/PI3K/mTOR pathway in which IGF-I induces the expression of myogenin protein (16), there is no evidence yet that the IGF-I/PI3K/ mTOR pathway is involved in myogenin protein induction in alveolar RMS.

In alveolar RMS Rh30 and MS cells, both of which had been confirmed to express $P A X 3-F K H R$, IGF-I $(50 \mathrm{ng} / \mathrm{ml})$ induced a remarkable increase of myogenin protein up to $48 \mathrm{~h}$ (Fig. 2). This prompted us to examine the signaling pathway downstream of IGF-IR for myogenin protein induction in these alveolar RMS cells. PI3K, Akt and mTOR serve as downstream mediators of IGF action on muscle differentiation in $\mathrm{C} 2 \mathrm{C} 12$ 
and L6 myoblasts (38-41). Our findings that both $\alpha \mathrm{IR}-3$ and rapamycin decreased myogenin protein induction by IGF-I (Fig. 3A and B) and that rapamycin did not inhibit the myogenin expression induced by IGF-I in Rh30mTOR-rr cells stably expressing a rapamycin-resistant mutant mTOR (Fig. 3C) indicate that IGF-I induces myogenin protein mainly through the IGF-IR/mTOR pathway and mTOR regulates the induction of myogenin in these alveolar RMS cells.

On the other hand, in embryonal RMS RD and KH cells, serum withdrawal appeared to induce an increase of myogenin protein up to $48 \mathrm{~h}$ after serum withdrawal, whereas IGF-I did not cause any additional induction (Fig. 4A and B). The p38MAPK pathway was previously shown to play a role in myogenesis in non-tumor mouse myoblast cells in a parallel but distinct route from the PI3K pathway (30-33). A p38MAPK inhibitor (SB203580) has been reported to inhibit the expression of myogenin in cardiac myoblast H9c2 cells (33). We found that a p38MAPK inhibitor (SB203580) completely inhibited myogenin protein induction by serum withdrawal in embryonal RMS RD and KH cells (Fig. 4C). These data indicate that serum withdrawal induces myogenin protein mainly through the p38MAPK pathway rather than through the IGF-IR/mTOR pathway in embryonal RMS cells.

Together, these results indicate that myogenin induction by serum withdrawal in alveolar RMS does not involve the p38MAPK pathway and that myogenin protein induction by IGF-I does not involve the IGF-IR/mTOR pathway in embryonal RMS cells. Because IGFs are naturally present in the human body, our results may also explain why alveolar RMS has a greater percentage of myogenin-positive tumor cells than embryonal RMS pathologically.

Because the levels of IGF-IR protein in alveolar and embryonal RMS cell lines used in this study were equal (data not shown), we further examined the phosphorylation status of effectors downstream of IGFI/mTOR signaling and found some differences between alveolar and embryonal RMS cells. Akt, 4E-BP1 and p70s6k have been identified as effectors of the IGF-IR/PI3K/mTOR signaling pathway (34-37). Some studies reported that p70S6K activity was not required for myogenesis and that myogenic differentiation was dependent on mTOR kinase function and the phosphorylation of 4E-BP1 by mTOR $(42,43)$. The phosphorylation statuses of Akt and p70s6k were not different between Rh30 and RD cells. We found that 4E-BP1 was constitutively hyperphosphorylated by IGF-I in alveolar RMS Rh30 cells at least up to $24 \mathrm{~h}$, whereas, in embryonal RMS RD cells, the phosphorylation of 4E-BP1 by IGF-I was transient; it was dephosphorylated by $24 \mathrm{~h}$ post stimulation. Here relatively small changes in 4E-BP1 phosphorylation caused an association of 4E-BP1 and eIF4E, resulting in an inhibition of myogenic differentiation in C2C12 cells (43). Thus, the different effects of IGF-I on myogenin induction in alveolar and embryonal RMS cells are not due to either the level of IGF-IR expression or the signaling status of Akt and p70s6k downstream of IGF-IR, but might be due to the difference of phosphorylation status of 4E-BP1 between alveolar and embryonal RMS cells.

In addition to myogenin expression, cell cycle arrest is also necessary for terminal muscle differentiation. In our study, both serum-withdrawal and IGF-I treatment induced complete cell cycle arrest in $\mathrm{C} 2 \mathrm{C} 12$ cells. However, in alveolar
RMS cells, serum-withdrawal did not induce cell cycle arrest, while IGF-I promoted cell cycle progression. Further, IGF-I did not cause any change of cell cycle phase distribution in embryonal RMS cells (Fig. 5).

In summary, our data suggest that IGF-I induces myogenin in both alveolar RMS cells and non-tumor myoblasts, but promotes G1-S cell cycle progression without terminal muscle differentiation only in alveolar RMS cells, and has little effect on myogenin induction or cell cycle progression in embryonal RMS cells. These different responses to IGF-I may help to explain the differences in myogenin staining between alveolar and embryonal RMS. Further, our findings suggest that a specific inhibitor of 4E-BP1 hyperphosphorylation might be a useful anti-tumor agent for alveolar RMS.

\section{References}

1. Enzinger FM and Weiss SW: Soft Tissue Tumor. 2nd edition. Mosby, St. Louis, pp448-488, 1989.

2. Newton WA, Gehan EA and Webber BL: Classification of rhabdomyosarcomas and related sarcomas. Pathologic aspects and proposal for a new classification - an Intergroup Rhabdomyosarcoma Study. Cancer 76: 1073-1085, 1995.

3. Galili N, Davis RJ, Fredericks WJ, Mukhopadhyay S, Rauscher FJ III, Emanuel BS and Rovera G: Fusion of a fork head domain gene to PAX3 in the solid tumour alveolar rhabdomyosarcoma. Nat Genet 5: 230-235, 1993.

4. Shapiro DN, Sublett JE, Li B, Downing JR and Naeve CW: Fusion of PAX3 to a member of the forkhead family of transcription factors in human alveolar rhabdomyosarcoma. Cancer Res 53: 5108-5101, 1993.

5. Anderson J, Gordon T, McManus A, Mapp T, Gould S, Kelsey A, McDowell H, Pinkerton R, Shipley J and Pritchard-Jones K: UK Children's Cancer Study Group (UKCCSG) and the UK Cancer Cytogenetics Group. Detection of the PAX3-FKHR fusion gene in paediatric rhabdomyosarcoma: a reproducible predictor of outcome? Br J Cancer 85: 831-835, 2001.

6. Sorensen PH, Lynch JC, Qualman SJ, Tirabosco R, Lim JF, Maurer HM, Bridge JA, Crist WM, Triche TJ and Barr FG: PAX3-FKHR and PAX7-FKHR gene fusions are prognostic indicators in alveolar rhabdomyosarcoma: a report from the children's oncology group. J Clin Oncol 20: 2672-2679, 2002.

7. Khan J, Bittner ML, Saal LH, Teichmann U, Azorsa DO, Gooden GC, Pavan WJ, Trent JM and Meltzer PS: cDNA microarrays detect activation of a myogenic transcription program by the PAX3-FKHR fusion oncogene. Proc Natl Acad Sci USA 96: 13264-13269, 1999.

8. Weintraub $\mathrm{H}$ : The MyoD family and myogenesis: redundancy, networks, and thresholds. Cell 75: 1241-1244, 1993.

9. Arnold $\mathrm{HH}$ and Braun T: Targeted inactivation of myogenic factor genes reveals their role during mouse myogenesis. Int J Dev Biol 40: 345-353, 1996.

10. Davis RL, Weintraub $\mathrm{H}$ and Lassar AB: Expression of a single transfected cDNA converts fibroblasts to myoblasts. Cell 51: 987-1000, 1987.

11. Wright WE, Sassoon DA and Lin VK: Myogenin, a factor regulating myogenesis, has a domain homologous to MyoD. Cell 56: 607-617, 1989.

12. Braun T, Buschhausen-Denker G, Bober E, Tannich E and Arnold HH: A novel human muscle factor related to but distinct from MyoD1 induces myogenic conversion in 10T1/2 fibroblasts. EMBO J 8: 701-709, 1989 .

13. Hasty P, Bradley A, Morris JH, Edmondson DG, Venuti JM, Olson EN and Klein WH: Muscle deficiency and neonatal death in mice with a target mutation in the myogenin gene. Nature 364: 501-506, 1993 .

14. Nabeshima Y, Hanaoka K, Hayasaka M, Esumi E, Li S and Nonaka I: Myogenin gene disruption results in perinatal lethality because of severe muscle defect. Nature 364: 532$535,1993$.

15. Florini JR, Ewton DZ and Roof SL: Insulin-like growth factor-I stimulates terminal myogenic differentiation by induction of myogenin gene expression. Mol Endocrinol 5: 718-724, 1991. 
16. Xu Q and $\mathrm{Wu} \mathrm{Z}$ : The insulin-like growth factor-phosphatidylinositol 3-kinase-Akt signaling pathway regulates myogenin expression in normal myogenic cells but not in rhabdomyosarcoma-derived RD cells. J Biol Chem 275: 36750-36757, 2000.

17. Cuenda A and Cohen P: Stress-activated protein kinase-2/p38 and a rapamycin-sensitive pathway are required for $\mathrm{C} 2 \mathrm{C} 12$ myogenesis. J Biol Chem 274: 4341-4346, 1999.

18. Kumar S, Perlham E, Harris CA and Tsokos M: Myogenin is a specific marker for rhabdomyosarcoma: An immunohistochemical study in paraffin-embedded tissues. Mod Pathol 13: 988-993, 2000.

19. Dias P, Chen B, Dilday B, Palmer H, Hosoi H, Singh S, Wu C, Li X, Thompson J, Parham D, Qualman S and Houghton P: Strong immunostaining for myogenin in rhabdomyosarcoma is significantly associated with tumors of the alveolar subclass. Am J Pathol 156: 399-408, 2000.

20. Cessna MH, Zhou H, Perkins SL, Tripp SR, Layfield L, Daines C and Coffin CM: Are myogenin and myoD1 expression specific for rhabdomyosarcoma? A study of 150 cases, with emphasis on spindle cell mimics. Am J Surg Pathol 25: 1150-1157, 2001.

21. Hostein I, Andraud-Fregeville M, Guillou L, Terrier-Lacombe MJ, Deminiere C, Ranchere D, Lussan C, Longavenne E, Bui NB, Delattre $\mathrm{O}$ and Conindre JM: Rhabdomyosarcoma: value of myogenin expression analysis and molecular testing in diagnosing the alveolar subtype: an analysis of 109 paraffin-embedded specimens. Cancer 101: 2817-2824, 2004.

22. Maloney EK, McLaughlin JL, Dagdigian NE, Garrett LM, Connors KM, Zhou XM, Blattler WA, Chittenden T and Singh R: An anti-insulin-like growth factor I receptor antibody that is a potent inhibitor of cancer cell proliferation. Cancer Res 63: 5073-5083, 2003.

23. El-Badry OM, Minniti C, Kohn EC, Houghton PJ, Daughaday WH and Helman LJ: Insulin-like growth factor II acts as an autocrine growth and motility factor in human rhabdomyosarcoma tumors. Cell Growth Differ 1: 325-331, 1990.

24. Toretsky JA and Helman LJ: Involvement of IGF-II in human cancer. J Endocrinol 149: 367-372, 1996.

25. Kalebic T, Tsokos M and Helman LJ: In vivo treatment with antibody against IGF-I receptor suppresses growth of human rhabdomyosarcoma and down-regulates p34cdc2. Cancer Res 54: 5531-5541, 1994.

26. Shapiro DN, Jones BG, Shapiro LH, Dias P and Houghton PJ: Antisense-mediated reduction in insulin-like growth factor-I receptor expression suppresses the malignant phenotype of a human alveolar rhabdomyosarcoma. J Clin Invest 94: 1235-1242, 1994.

27. Hosoi H, Dilling MB, Lui LN, Shikata T, Sekulic A, Abraham RT, Lawrence JC Jr and Houghton PJ: Studies on the mechanism of resistance to rapamycin in human cancer cells. Mol Pharmacol 54: 815-824, 1998.

28. Hosoi H, Dilling MB, Shikata T, Lui LN, Shu L, Ashmun RA, Germain GS, Abraham RT and Houghton PJ: Rapamycin causes poorly reversible inhibition of mTOR and induces p53independent apoptosis in human rhabdomyosarcoma cells. Cancer Res 59: 886-894, 1999.

29. Luo W, Sharif TR and Sharif M: Substance P-induced mitogenesis in human astrocytoma cells correlates with activation of the mitogen-activated protein kinase signaling pathway. Cancer Res 56: 4983-4991, 1996.
30. Pier LP: Induction of terminal differentiation by constitutive activation of p38MAP kinase in human rhabdomyosarcoma cells. Gene Dev 14: 574-584, 2000.

31. Wu Z, Woodring PJ, Bhakta KS, Tamura K, Wen F, Feramisco JR, Karin M, Wang JY and Puri PL: p38 and extracellular signal-regulated kinases regulate the myogenic program at multiple steps. Mol Cell Biol 20: 3951-3964, 2000.

32. Yael T and Eyal B: Phosphoinositide 3-kinase induces the transcriptional activity of MEF2 protein during muscle differentiation. J Biol Chem 275: 34424-34432, 2000.

33. Lee J, Hong F, Kwon S, Kim SS, Kim DO, Kang HS, Lee SJ, Ha J and Kim SS: Activation of p38 MAPK induces cell cycle arrest via inhibition of Raf/ERK pathway during muscle differentiation. Biochem Biophys Res Commun 298: 765-771, 2002.

34. Gingras AC, Raught B and Sonenberg N: eIF4 initiation factors: effectors of mRNA recruitment to ribosomes and regulators of translation. Annu Rev Biochem 68: 913-963, 1999.

35. Jefferies HB, Reinhard C, Kozma SC and Thomas G: Rapamycin selectively represses translation of the 'polypyrimidine tract' mRNA family. Proc Natl Acad Sci USA 91: 4441-4445, 1994.

36. Terada N, Patel HR, Takase K, Kohno K, Nairn AC and Gelfand EW: Rapamycin selectively inhibits translation of mRNAs encoding elongation factors and ribosomal proteins. Proc Natl Acad Sci USA 91: 11477-11481, 1994.

37. Iiboshi Y, Papst PJ, Kawasome H, Hosoi H, Abraham RT, Houghton PJ and Terada N: Amino acid-dependent control of p70s6k: Involvement of tRNA aminoacylation in the regulation. J Biol Chem 274: 1092-1099, 1999.

38. Sumitani S, Goya K, Testa RJ, Kouhara H and Kasayama S: Akt1 and Akt 2 differently regulate muscle creatine kinase and myogenin gene transcription in insulin-induced differentiation of C2C12 myoblasts. Endocriology 143: 820-828, 2002.

39. Coolican SA, Samuel DS, Ewton DZ, McWade FJ and Florini JR: The mitogenic and myogenic actions of insulin-like growth factors utilize distinct signaling pathways. J Biol Chem 272: 6653-6662, 1997

40. Jiang BH, Zheng JZ and Vogt PK: An essential role of phosphatidylinositol3-kinase in myogenic differentiation. Proc Natl Acad Sci USA 95: 14179-14183, 1998.

41. Jiang BH, Aoki M, Zheng JZ, Li J and Vogt PK: Myogenic signaling of phosphatidylinositol 3-kinase requires the serinethreonine kinase Akt/protein kinase B. Proc Natl Acad Sci USA 96: 2077-2081, 1999.

42. Canicio J, Gallardo E, Illa I, Testar X, Palacin M, Zorzano A and Kaliman P: p70 S6 kinase activation is not required for insulin-like growth factor-induced differentiation of rat, mouse, or human skeletal muscle cells. Endocrinology 139: 5042-5049, 1998.

43. Shu L, Zhang X and Houghton PJ: Myogenic differentiation is dependent on both the kinase function and the N-terminal sequence of mammalian target of rapamycin. J Biol Chem 277: 16726-16732, 2002. Epub Mar 12002. 